\title{
El Patrimonio como Tecnología para la Producción y Gestión de Identidades en la Sociedad del Conocimiento ${ }^{1}$
}

\author{
Heritage as a Technology for the Production and Management of \\ Indentities in Knowledge Societies
}

Daniel Muriel ${ }^{2}$

\begin{abstract}
Resumen
Este articulo busca presentar el patrimonio cultural como una herramienta de (re)construcción del sentido y de las identidades en la sociedad contemporánea, marcada precisamente por la pérdida de los grandes referentes de sentido y la multiplicación de identidades de carácter precarios, fragmentarios, contingente. Para ello se describe un escenario social atravesado por el conocimiento experto $y$ las racionalidades politicas postmodernas, donde se configura, de manera explicita, un espacio especifico manejable por el experto: la identidad. Después, el texto se centra en el caso del patrimonio cultural como tecnología para la producción y gestión de identidades, especificando, con fines analiticos, algunos de sus modelos de actuación.
\end{abstract}

Palabras clave: patrimonio cultural, identidad, sociedad del conocimiento, sociología de la ciencia, gubernamentalidad.

\section{Abstract}

This paper aims to introduce cultural heritage as a tool oriented to the (re)construction of meaning and identities in contemporary society, which can be defined by the loss of the great social referents and the multiplication of precarious, fragmentary and contingent identities. It describes a social scenario where expert knowledge and postmodern political rationalities are capital is-

1 La redacción de este artículo se ha realizado bajo la financiación del Gobierno Vasco, a través de una beca de Formación de Personal Investigador del Departamento de Educación, Universidades e Investigación.

2 Centro de Estudios sobre la Identidad Colectiva, Departamento de Sociología 2, Universidad del País Vasco. Email: danimuriel@yahoo.es

Recibido: Marzo 2008. Aceptado: Octubre 2008. 
sues for its understanding. In this scenario is set up, in an explicit way, an specific and easy to handle space by the expert: identity. Later, the text focuses on cultural heritage as a technology for the production and management of identities, describing some of its forms of action.

Key words: heritage, identity, knowledge society, sociology of science, governmentality

\section{INTRODUCCIÓN}

Siguiendo la línea temática marcada para este número por el comité de esta revista, mi intención es la de presentar un texto que dé cuenta de la importancia del patrimonio cultural en las sociedades contemporáneas. Para ello, orientaré el presente artículo en la dirección de los objetos de interés en los que he venido trabajando últimamente, y que tienen que ver con la manera en la que se construyen las identidades en los nuevos escenarios sociales, como puede ser la sociedad del conocimiento. Así, el caso que trataré aquí será el del patrimonio cultural como tecnología, sostenida por complejas redes expertas, para la producción, modificación y gestión de las identidades colectivas e individuales.

Por lo tanto, esos serán los ingredientes teóricos que utilizaré en la siguiente receta sociológica: todo un cóctel de conceptos que intentaré ubicar y disponer adecuadamente sobre los escenarios de la sociedad del conocimiento. Puesto que el espacio de exposición es limitado, y ante la densidad de las nociones traídas a colación, se deberá entender este artículo como un intento por mostrar un esbozo más o menos coherente de algunas de las principales líneas teóricas que estoy desarrollando en la actualidad.

El orden de exposición será el siguiente: en primer lugar, se intentará dibujar el esquema de las condiciones sociales de existencia contemporáneas que me interesa resaltar, lo que me llevará a abordar brevemente la noción de sociedad del conocimiento y las implicaciones que conlleva la asunción de la existencia de este escenario; en segundo lugar, se abordará, dentro del contexto descrito, el desarrollo de la idea del patrimonio como dispositivo diseńado para la construcción y manejo de las identidades, exponiendo una propuesta analítica de los modos en los que aquél puede actuar sobre estas últimas. 


\section{LA IDENTIDAD COMO ESPACIO MANEJABLE POR EL EXPERTO EN LA} SOCIEDAD DEL CONOCIMIENTO

Muchos han sido los esfuerzos realizados por la teoría social en las últimas décadas para intentar tejer un entramado teórico sobre el cambio de época que se atisba, especialmente, desde mediados del siglo XX. Por ello, y como éste no es el lugar en el que iniciar tales debates, partiré de la hipótesis sociedad del conocimiento, que ni agota en ningún caso las múltiples posibilidades y perspectivas desde las que se puede abordar la realidad social contemporánea, ni tampoco pretende mostrarse como un modelo teórico que pueda identificarse con la totalidad de los múltiples aspectos que un cambio de época implica. En cualquier caso, utilizo aquí la sociedad del conocimiento como una herramienta conceptual útil que nos permite pensar determinadas problemáticas contemporáneas.

Para ubicar de forma mínima esta hipótesis, tomo aquí el sentido que le han dado a la etiqueta sociedad del conocimiento autores como Lamo de Espinosa (1996) o Stehr (1994), quienes tras la senda de la sociedad postindustrial de Bell (1994), se centran en el papel fundamental que juega el conocimiento científico en la sociedad actual, aunque mis planteamientos teóricos se desmarquen en muchas ocasiones de sus premisas y yo haya engarzado algunas de sus disquisiciones con otras corrientes teóricas como la neofoucaultiana (Rose, Miller, Dean) o la sociología de la ciencia (Latour, Woolgar, Callon).

De cualquier modo, y a riesgo de simplificar en exceso, me desmarco así de otra literatura que ha abordado la sociedad del conocimiento solamente desde los estudios de las nuevas tecnologías de la información y la comunicación, entendiendo, por ejemplo, la sociedad del conocimiento como una extensión sofisticada de la sociedad de la información de Castells (2000, 2001a, 2001b), o desde una vertiente propia de los estudios dentro del área del management, cuyo precursor ha sido Drucker (1998) y su visión postcapitalista de una sociedad del saber, generalmente orientada a la redacción de manuales sobre gestión del conocimiento en el mundo empresarial ${ }^{3}$.

De esta manera, entiendo que los dos ejes principales que definen la sociedad del conocimiento son los siguientes: la emergencia de una creciente

3 Otra forma de clasificar los distintos modelos teóricos que abordan la sociedad del conocimiento lo podemos encontrar en Seguel (2005), donde se atiende a un criterio que discrimina según las metáforas sociológicas bajo las que se presenta: sociedades de la reflexividad y sociedades de complejidad. 
cultura científico-experta y la aparición de un tipo de gubernamentalidad postmoderna.

\section{Cultura Experta}

La asunción de que, cada vez más, una incipiente cultura experta se está asentando en nuestras sociedades reside, por un lado, en el predominio del conocimiento científico ${ }^{4}$, y por otro lado, en el desarrollo de complejas redes expertas.

Se puede considerar que el conocimiento científico ha inundado cada recoveco de la sociedad, se ha filtrado por todos sus poros, y apenas ha obviado resquicio alguno debido a su capacidad para traducirse y su habilidad para generar posos de legitimidad, estableciendo rutinas y disciplinas en torno a su ejercicio y a sus productos. Su eficiencia a la hora de copar todos los espacios de la realidad social estriba, en parte, en su versatilidad, ya que el conocimiento científico ha desarrollado distintas formas para extenderse a través de lo social como:

- las inscripciones, entiéndase como ese conjunto de textos, diagramas, trazos, manchas, números registrados, mapas, fotografías, informes, etc., que (re)combinadas pueden generar más inscripciones ad infinitum, y que, alineándose, crean referencias circulantes (Latour 2001). Unas inscripciones que son fácilmente transportables, comparables y estandarizables, lo que explica su capacidad para inscribir conocimiento sobre cualquier aspecto de la realidad social. Por lo tanto no debería sorprendernos encontrarnos rodeados de infinitos estudios científicos sobre cualquier materia, que nos invadan números y estadísticas sobre toda clase de problemáticas o que se recuerde la más nimia de las efemérides.

- las cajas negras, es decir, esos compactos contenidos de conocimiento del que sólo nos preocupan, a lo sumo, los datos de entrada que introducimos y la salida que éstos producen. Por ejemplo, el televisor. Nosotros sabemos utilizar el botón de encendido y apagado, cambiar los canales desde el mando a distancia o subir y bajar el volumen. Seguramente lo más complicado que podemos llegar a hacer con nuestra televisión es sintonizar los canales. Y todo ello sin necesidad de saber nada acerca de infrarrojos, física electromagnética o programación de circuitos integrados. De esta manera, lo único que desplegamos nosotros son pautas de conocimiento práctico

4 En otro lugar discuto sobre la sociedad del conocimiento como vía plausible después de la crisis de la modernidad, y en el que ahondo más en estas cuestiones (Muriel 2005). 
que nos permiten desenvolvernos en la maraña del conocimiento científico reificado que nos rodeas.

Este sustrato común de lo científico-técnico que lo envuelve todo, se desarrolla a través de la instauración de complejas redes expertas, que son el verdadero objeto de estudio que debe abordarse si se desea investigar la importancia que el conocimiento científico posee en las sociedades contemporáneas. Y es que no sólo se trata de movilizar a grandes cantidades de técnicos y científicos interconectados, trabajando en sus laboratorios, en sus grupos de investigación, en sus departamentos o en cualquier otra entidad dedicada al estudio científico, pública o privada, sino que además estas redes implican el seguimiento de multitud de normas, rutinas, pautas y protocolos, por no hablar de las tecnologías y toda clase de herramientas que son necesarias en la labor técnica que se desarrolla. En cualquier caso, las redes expertas forman imbricadas redes socio-técnicas en las que se conjugan las condiciones socio-materiales de producción del conocimiento que tanta importancia posee en las sociedades de hoy día.

Además, en una hipotética sociedad del conocimiento la imagen del experto aislado no resulta fecunda, algo consumado por la diferencia de envergadura que se produce en la transición entre las maneras de hacer ciencia a finales del XIX o principios del XX de la actualidad:

El resultado es, de una parte, el tránsito desde la pequeña ciencia realizada por pioneros o profesores en pequeños laboratorios artesanales, a la gran ciencia, que moviliza gigantescos recursos no sólo materiales, sino también humanos, en la que el diseño y ejecución de un experimento puede implicar a cientos, si no a miles, de cientificos y técnicos (Lamo de Espinosa, 1996: 127).

Por lo tanto, la sociedad del conocimiento no es la del sujeto cognoscente, la del científico aislado o la del intelectual totalizador, figuras más propias de otras épocas.

En definitiva, la predominancia del conocimiento científico y la proliferación de grandes redes expertas desembocan en una cultura experta que crea sujetos habituados y disciplinados, no sólo a la hora de seguir los protocolos para hacer ciencia como parte de una red experta, sino también cuando se desenvuelven cotidianamente con los artefactos y códigos técnico-expertos que pueblan las sociedades contemporáneas.

\footnotetext{
5 Es lo que Latour y Woolgar (1995:79), siguiendo a Bachelard, denominan "teoría reificada”.
} 


\section{Gubernamentalidad Postmoderna}

El otro eje que me gustaría reseñar sobre la sociedad del conocimiento es la aparición de un tipo de gubernamentalidad postmoderna, anclada en una suerte de racionalidad política neo-liberal que busca principalmente gobernar a través de la libertad individual. Este planteamiento sigue las aproximaciones neo-foucaultianas de autores como Rose (1999a, 1999b, 2007), Miller y Rose (1992) o Dean (1999), que identifican lo que puede ser considerado la racionalidad política contemporánea: el neo-liberalismo o liberalismo avanzado. Esta nueva racionalidad política sigue la lógica del panóptico llevada al paroxismo, que acaba por superarla: la autorregulación alcanza su máximo nivel ya que "los individuos pueden ser gobernados a través de su libertad para elegir" (Miller y Rose 1992: 201) ${ }^{6}$. Libertad y control, autonomía individual y gobierno, son pares que no se encuentran reñidos, forman parte indisociable de una nueva fórmula en el manejo de realidades poblacionales.

Nos encontraríamos, pues, en un modelo postpanóptico, una época marcada por el "control abierto y continuo" (Tirado y Gálvez 2004). En definitiva, el panóptico, por mor de su éxito, ha quedado completamente descentrado, como si hubiera explosionado en un sinnúmero de pequeños pedazos cada cual con sus capacidades de vigilancia intactas, y es que ahora todos, humanos y no-humanos en sus infinitas combinaciones, pueden observarse entre sí, controlarse mutuamente sin que así lo parezca. Ya no es necesario el encierro en un espacio delimitado para la labor de vigilancia, y sin embargo, ésta, se vuelve exhaustiva hasta el detalle, se torna en perfecta trazabilidad. Ahora estamos más sujetos a la mirada que nunca, pero ahora más que nunca no estamos sujetos a ninguna mirada concreta: es el ojo múltiple, que por puro diluido parece que no existe, pero nos vigila constantemente.

Entonces, la pregunta a hacerse es la siguiente: ¿cómo gobernar una serie de dominios sin destruir su autonomía? El experto, el actor social por excelencia en una sociedad del conocimiento, llevaría a cabo una especie de doble alianza: por un lado, con las autoridades políticas, traduciendo sus problemas económicos, sanitarios o de orden social en un vocabulario de la gestión, de la contabilidad, de la medicina o de la ciencia social; por otro lado, podrían aliarse con los ciudadanos traduciendo sus inquietudes diarias a un lenguaje que les permitiera manejarse mejor en su vida cotidiana (Miller y Rose, 1992: 188). Por lo tanto, en la sociedad del conocimiento,

6 Las traducciones al español de las citas en inglés son propias. 
la gubernamentalidad reviste fórmulas postpanópticas de poder en el que el conocimiento científico-técnico y la figura del experto son indispensables para llevarse a cabo.

Siendo ese el armazón general de una gubernamentalidad postmoderna, aquí, además, señalaremos la tendencia que puede observarse de un tiempo a esta parte respecto a lo que puede considerarse que es un nuevo campo de acción directa para las cuestiones de gobierno, o lo que es lo mismo, cómo se está problematizando un nuevo espacio sujeto a la acción biopolítica: la identidad. Rose (1999), siguiendo los desarrollos de la teoría foucaultiana por parte de Poovey y Millar, destaca la existencia de unos "espacios abstractos" que caracterizan los espacios gobernables: poblaciones, naciones, sociedades, economías, clases, familias, escuelas, factorías, individuos. Cabe pensar, pues, que dentro de la naturaleza de estos espacios abstractos, aparezca la propia identidad, que se convierte entonces en espacio gobernable y supeditado a toda clase de operaciones de racionalización experta, buscándose, por lo tanto, su inteligibilidad, su contabilidad, su movilidad y su maleabilidad.

Refinando más nuestro instrumental conceptual, deberíamos afirmar que estamos ante semiopoliticas o biopoliticas del sentido. Debemos recordar que el principal objetivo buscado con la biopolítica es la maximización de las fuerzas sociales, dotando de higiene, seguridad, longevidad, comodidad, prosperidad, u orden a las poblaciones. Hoy día, habiendo cubierto de manera muy desigual esas necesidades, una desigualdad especialmente visible entre los países ricos y aquellos en vías de desarrollo, poco a poco se va extendiendo allí donde se ha configurado un nuevo lugar para la omnívora apetencia de la racionalización y el conocimiento científico: la creación y gestión de identidades.

No es de extrañar, pues, que se disponga la identidad como campo de acción del experto y las biopolíticas, ya que entra perfectamente dentro de una lógica que pretende formar subjetividades que se autorregulen, que se gobiernen a través de su propio derecho individual a elegir, ya sea trabajo, seguridad, salud, residencia y, por qué no, también sus propias identidades.

\section{Consecuencias "Reales" del Nuevo Escenario}

La definición de este nuevo escenario implica, al menos, dos consecuencias de gran calado que hay que tener en cuenta si se desea abordar cualquier temática en dicho contexto. 
En primer lugar, la realidad es colonizada por la ciencia, ya que la mayoría de la comprensión de la realidad que nos rodea se encuentra mediada, en mayor o menor medida, por los discursos y prácticas tecnocientíficas. Lo que implica que, por un lado, todo necesite pasar por las manos de los expertos para que algo alcance algún tipo de status de realidad, evidentemente, sólo hasta cierto punto porque la ciencia es poderosa pero no omnipotente, $y$, por otro lado, que la realidad se está convirtiendo en un gran laboratorio en sí misma, tal y como podemos observar en la incesante proliferación de investigaciones y estudios sobre toda clase de asuntos y materias.

De esa consecuencia puede extraerse otra, propia del nuevo escenario descrito, y que es la existencia de una creciente reflexividad que hace de la realidad algo inestable. Una inestabilidad causada, entre otros procesos, por la acción reflexiva a través de la cual el simple acto de conocer algo transforma lo que está siendo conocido. La realidad (aquí, una sociedad, un grupo o una comunidad) absorbe los enunciados que se hacen sobre ella y las acciones que se llevan a cabo en su superficie, conduciéndose a sí misma en función de ello, en muchas ocasiones, contestando este conocimiento sobre sí, lo que requiere la creación de nuevo conocimiento que reinicia el proceso de nuevo.

Por lo tanto, resulta necesario que modifiquemos nuestro instrumental de análisis con la intención de acercarnos a esos espacios de realidad que resisten la mirada, ya que nuestros objetos de estudio no son tan estáticos ni tan duros como creíamos, son huidizos y resbaladizos, y se nos enfrentan de muy diversas formas. Esto es especialmente cierto cuando tratamos con temas relacionados con la identidad: ya no existe una identidad unívoca que comprenda todos los significados para un individuo o grupo, las identidades se han vuelto fragmentadas, flexibles, cambiantes.

Teniendo en cuenta estas consecuencias, no está de menos realizar una breve reflexión acerca de la definición de sociedad del conocimiento que he dado más arriba, puesto que tal y como yo la entiendo, no se trata de una sociedad caracterizada principalmente por encontrarse siempre en un constante progreso y donde todo el mundo posee grandes cantidades de conocimiento; esa, en ocasiones, casi beatífica imagen de la sociedad contemporánea que algunos defienden. Al contrario, la sociedad del conocimiento precisamente se encuentra marcada por el desencanto con el pensamiento ilustrado, donde ya no existe un Santo Grial que alcanzar, como la emancipación del hombre o la paz perpetua, basadas en la ideolo- 
gía del progreso. Por supuesto, cada vez hay más cantidad de conocimiento y existen multitud de objetivos que cumplir, pero ya no son partes de una metanarrativa que los explique todos. La sociedad del conocimiento no es teleológica sino tautológica. Es como si únicamente pudiera generar más y más conocimiento porque fuera lo único que nos queda: la maquinaria científica para producir conocimiento sobre conocimiento, construyendo realidades sobre realidades previas. Mi idea de la sociedad del conocimiento es más ambigua y oscura que entusiasta.

Resumiendo esta primera parte del artículo, la sociedad del conocimiento es el momento socio-histórico en el que la institucionalización de la biopolítica y la creación de una cultura experta alcanzan su apoteosis, en el que no existe apenas superficie que no haya sido colonizada por las técnicas de gobierno y la labor del experto, y en el que sólo nos queda volver una y otra vez sobre los artefactos tecnocientíficos que vamos depositando sobre la realidad. Al menos aún nos queda explorar nuevas formas de hacer ciencia, de construir conocimiento de aquello que elude la mirada técnica, incluso, de estudiarnos a nosotros mismos como expertos.

\section{EL PATRIMONIO COMO TECNOLOGÍA PARA LA PRODUCCIÓN Y GESTIÓN} DE IDENTIDADES

\section{Del Patrimonio-Hacienda al Patrimonio Cultural}

A continuación trasladaré todas estas cuestiones generales a un ejemplo concreto, el del patrimonio como tecnología que permite producir, modificar y gestionar identidades. Antes de comenzar con ello, cabe realizar una pequeña genealogía del patrimonio. Después, se observarán las transiciones y ampliaciones que ha sufrido el concepto original de patrimonio hasta convertirse hoy día en el sintagma patrimonio cultural y cómo se presenta como una herramienta para la reconstrucción del sentido y las identidades.

Etimología de la voz "patrimonio" y su tránsito hacia el sintagma "patrimonio cultural"

$\mathrm{Si}$ atendemos a su significado original, la voz patrimonio en español, al igual que la palabra patrimoine en francés, procede del latín patrimonium, que venía a referirse al "conjunto de los bienes que poseía el paterfamilias" (Bermejo 2005), unos bienes que, en definitiva, se poseen de los padres, es decir, que son heredados del padre (Ballart y Tresserras 2005: 11). Según 
Santamarina (2005: 21), el patrimonio remitiría a una "categoría económica y jurídica de larga tradición histórica", que implicaría la "transmisión de bienes de nuestros antepasados". El patrimonio es, pues, según esta etimología, principalmente una cuestión económica regulada legalmente, un inventario de propiedades económicamente valiosas formulado según un código de derecho.

Si nos paramos a analizar términos similares al patrimonio en otros idiomas, es posible observar numerosas coincidencias. Así, la voz inglesa heritage (del galicismo héritage, que a su vez procede del latín, hereditarius) queda definida como aquello que ha sido o puede ser heredado, o también, como aquellas circunstancias o beneficios que pasan de una generación a otra (Howard 2003: 6). De nuevo, la cuestión de la herencia, del legado, de lo valioso.

Vemos entonces los antecedentes conceptuales del patrimonio que pueden resumirse en la siguiente carga semántica: propiedad (que se posee), herencia (que se hereda de los padres), valor (que tiene un valor económicamente ponderable) y derecho (en un doble sentido: por un lado, que es justo, legítimo; por otro lado, que su legitimidad es ordenada legalmente, es decir, regulada según códigos pertenecientes a la legalidad). Por lo tanto, $e l$ patrimonio es una posesión valiosa legitimamente heredada y legalmente protegi$d a$. Otros aspectos interesantes a señalar son que, a pesar de que el conjunto de bienes procede de una especie de entidad colectiva, la familia, su titularidad es individual una vez heredado y, en todo caso, pertenece al ámbito de la privacidad. He aquí más aspectos que definen a esta noción primigenia de patrimonio: individual, privada, y por lo tanto, algo que no tiene por qué ser hecho público, visible para los demás, salvo aquellos a los que el propietario considere oportunos. De hecho, el desarrollo de este concepto en el ámbito técnico-jurídico indica estrictamente "un conjunto de bienes económicamente valorables, agrupados por su común pertenencia a un sujeto o afectos a un fin" (Ariño 2002: 334).

Éste sería, entonces, el significado original de la palabra patrimonio, que en este texto he convenido en llamar, a efectos de su diferenciación con el concepto de patrimonio que aquí analizo en el contexto de la sociedad del conocimiento, patrimonio-hacienda. Se trata de resaltar el uso del patrimonio designado como el "conjunto de bienes y riquezas que alguien tiene"

Búsqueda del término "hacienda" en la RAE: http://buscon.rae.es/draeI/SrvltGUIBusUsual? TIPO_ HTML=2\&LEMA=hacienda 
Una vez realiza la breve etimología del concepto patrimonio, vemos que, sin embargo, hoy día, la palabra patrimonio tiene significados adicionales asociados al sintagma patrimonio cultural, que es parcialmente producto de una traslación en los significados y una ampliación de los usos del patrimonio-hacienda clásico:

- De lo individual a lo colectivo. Se ha pasado del paterfamilias o de la persona física o jurídica, a la nación, la comunidad, el pueblo o la humanidad como titulares del patrimonio.

- De lo privado a lo público. El patrimonio-hacienda es una cuestión que se mueve dentro del ámbito de lo privado, y por lo tanto, no es algo que deba hacerse necesariamente visible. El patrimonio cultural, al pasar a ser un tipo especial de propiedad colectiva, pertenece a la esfera de lo público y, por ende, de lo visible, en muchas ocasiones, de lo espectacular y teatralizado.

- Ampliación de las formas valorativas del patrimonio. Sigue siendo un conjunto de elementos sujeto a algún tipo de estimación valorativa (el patrimonio es algo necesariamente valioso, al menos en las poderosas retóricas que lo envuelven), pero ya no simplemente económica, ya que puede revestir un valor histórico, social, cultural, estético, artístico, antropológico, científico o natural, entre otros muchos.

- La creciente importancia de lo inmaterial y lo simbólico, que se une así a la clásica preocupación por el legado material. De una preocupación estrictamente económica o sentimental por la posesión y conservación de unos bienes de índole material, a una preocupación por la preservación de elementos simbólico-culturales, entre los que cada vez destacan más las representaciones en las que predomina la llamada carga inmaterial (lenguas, tradiciones, fiestas, formas específicas de hacer o practicar algo, acontecimientos pasados).

Por lo tanto, puede afirmarse que actualmente conviven dos conceptos del patrimonio por separado: por un lado, el patrimonio como hacienda, como riqueza individual, utilizado desde hace siglos con escasas variaciones semánticas; por otro lado, el patrimonio como herencia cultural, es decir, como ese conjunto de monumentos, obras artísticas, construcciones, yacimientos, lugares, creencias, paisajes, prácticas, formaciones biológicas y un largo etcétera de elementos diversos que merecen ser conservados por algún tipo de criterio y que es un concepto que, tal y como lo considero, emerge alrededor del ecuador del siglo XX y es consolidado en su último cuarto. Por 
lo tanto, el patrimonio cultural, sería la acepción moderna o postmoderna del patrimonio.

Pero esta traslación de significados, el uso metafórico del concepto original del patrimonio sobre una problemática contemporánea, no puede entenderse si no se tienen en cuenta algunas consideraciones que envuelven el nuevo tipo de sociedad en el que nos encontramos. Sólo en una época en la que existe la percepción de una pérdida generalizada y una dificultad para consignar espacios de sentido, unido todo ello a la ruptura histórica que provoca el desmoronamiento de la idea de progreso, es donde puede aparecer el patrimonio cultural, especialmente como tecnología para manipular y gestionar sentidos, afectos, identidades. Es cierto que, tras la Revolución Francesa, a finales del XVIII, y sobre todo, ya entrado el siglo XIX con la corriente romántica, aparece una conciencia histórica que se preocupa por lo anterior, y que teme que grandes partes del pasado y del presente se disuelvan en la vorágine de los acontecimientos modernos. Es ahí donde muchos autores sitúan el nacimiento del patrimonio, considerando que tras la Segunda Guerra Mundial se produce una intensificación del fenómeno, identificado como "boom patrimonial" (Arińo, 2002: 329). Es la ya clásica tesis de Lowenthal (1985), por la que se generaliza un sentimiento de pérdida postrevolucionario (Revolución Francesa, Revolución Industrial).

Admito que había una preocupación previa por el pasado, y que incluso existían prácticas como los actos de coleccionar y preservar objetos materiales, además de existir dispositivos como los museos, los archivos y las galerías, hoy todos ellos relacionados con el patrimonio. No obstante, considero que esas eran prácticas, objetos y dispositivos aislados, y en ningún momento, fueron vinculados conjuntamente bajo la etiqueta del patrimonio, ya que eso sólo ocurre alrededor del ecuador del siglo XX, momento en el que se utiliza metafóricamente la voz patrimonio para referirse a un activo de índole cultural, artística, histórica, etnográfica, o natural entre otros ejemplos. En esta presentación no entraré a discutir si la aparición del patrimonio tal como lo entendemos ahora, como patrimonio cultural (o patrimonio histórico, artístico, etnográfico, natural, arquitectónico, etc.), se remonta más allá de un siglo o tan sólo a los últimos cincuenta años, ya que eso nos desvía de la cuestión central en este texto, que no es otra que mostrar el patrimonio como una tecnología genérica para hacer y manejar identidades. 
Así, obviando el primer significado del patrimonio, el que lo entiende como hacienda personal, nos encontramos con dos variantes semánticas del término, ahora adjetivado como cultural, que constituyen la encrucijada fundamental en la que se encuentra la identidad en las sociedades actuales: por un lado, el patrimonio como configuración, como la disposición de un conjunto de bienes simbólico-materiales que conforma el sustrato del valor diferencial de una identidad; por otro lado, el patrimonio como tecnología, como el proceso activo por el que se construye esa diferencia identitaria, se mantiene y se gestiona. Siendo así, cabe pensar en el patrimonio no sólo como lo que compendia las cosas que valen sino también como los procedimientos que hacen de esas cosas algo valioso (Gatti y Muriel 2006: 65). Un sentido pasivo del patrimonio frente a otro activo.

En cualquier caso, es evidente que esta forma de abordar el patrimonio, como una tecnología sostenida por complejas redes expertas, no agota todos los modos de acercarse a su realidad. Habría que tener en cuenta otros discursos y prácticas no expertos, que en muchas ocasiones son los que proveen al experto en patrimonio con la materia prima que procede de ese mundo cultural, el de la tradición, que él plasma adecuadamente según los códigos imperantes en la sociedad del conocimiento.

\section{El patrimonio cultural como reconstructor de sentido e identidades}

Esta forma de entender el patrimonio como dispositivo, únicamente puede surgir cuando el sentimiento de pérdida es total, cuando ya no existen referentes (ni pasados, ni presentes, ni futuros) sólidos sobre los que cimentar algún tipo de estrategia encaminada a la generación de sentido. $Y$ esto sólo ocurre, con la correspondiente prudencia, tal y como he mencionado anteriormente, alrededor del comienzo de la segunda mitad del siglo $\mathrm{XX}$, momento en el que se pueden atisbar unas nuevas condiciones de posibilidad, esas que también nos conducen a la hipótesis de la sociedad del conocimiento.

Y es que uno de los aspectos sintomáticos de esta nueva época, es la experiencia de la pérdida: pérdida del sentido (semántica y rumbo), pérdida de la realidad; y los vacíos y ausencias que ello provoca: deambular errático del individuo, dificultad para dar sentido a la existencia, problematización y puesta en cuestionamiento de lo real (Baudrillard, 1984); por no hablar de los miedos que evoca: conciencia de riesgo (Beck, 1998), temor al vacío. Y dentro de esas pérdidas, ausencias, y temores, los de la pérdida de lo anterior, 
los de la ausencia de un legado que dote de sentido el presente y oriente el futuro, y los del miedo al vacío histórico.

Entonces, ¿cómo llevar a cabo estrategias de producción de sentido, precisamente en unas condiciones de posibilidad en las que la propia generación de estos espacios es lo problemático? Es aquí donde entra en juego el patrimonio como unos de los instrumentos sociotécnicos destinados a la reconstrucción parcial del sentido. El patrimonio es, por lo tanto, un intento de suturar mecánicamente algunas de las heridas descarnadas de la modernidad, de llenar artefactualmente sus vacíos y ausencias, o de construir un armazón tecnológico cuya finalidad sea la de protegernos de ciertos riesgos contemporáneos y disipe parte de nuestros miedos a la pérdida completa del sentido.

Resulta conveniente aclarar, también, que el patrimonio no tiene por qué llegar a una fórmula de reconstrucción o de restitución. Ni tan siquiera de remiendo o parche. En ocasiones, basta con recoger pedazos inconexos, o hacer del propio socavón, crisis o herida, formas que generen su propio sentido, aunque sea el del collage, el del vacío, el de la supuración, el de la grieta. El patrimonio no deja de ser una tecnología propia de su tiempo, de las racionalidades políticas que lo envuelven, formando parte de una realidad en la que emergen sujetos e identidades descentrados, múltiples y fragmentados.

\section{Modalidades de Actuación del Patrimonio sobre las Identidades}

Entonces, lo que he expuesto hasta ahora podría resumirse de la siguiente manera: nos encontramos en una época marcada por el conocimiento experto, la inestabilidad de la realidad, y los esfuerzos dirigidos a gobernar una realidad cambiante preñada de sentimientos de pérdida, vacío y miedo. De este modo, basadas en la labor experta y científica, existen herramientas que han sido desarrolladas con la intención de actuar bajo esas circunstancias. Una de ellas es el patrimonio como instrumento, una tecnología para producir, modificar o gestionar identidades. Desde un estricto punto de vista analítico, aquí propondré que, en términos generales, el patrimonio logra aparecer como una tecnología que actúa sobre las identidades a través, básicamente, de cuatro formas que detallo a continuación:

- la primera, funcionando como una fórmula extrema de biopoder, que se aplica a la realidad semiótico-material sobre la que se ejerce la posibilidad de revivir, de volver a traer a la vida, mundos sociales y realidades 
extintos, permitiendo, excepcionalmente, zonas en las que se puede dar cabida a lo que, en las condiciones sociales y materiales contemporáneas, ya no tiene lugar.

- la segunda, haciendo de la identidad algo manejable, maleable, convirtiéndola en rutina, en algo que pude ser trascrito a los códigos de la homologación, de la fórmula, de lo reproducible, de lo exportable e incluso de lo comercializable.

- la tercera, haciendo del propio patrimonio un lugar para la canalización, y eventual resolución, de las diversas disputas sobre la identidad y la memoria.

- la cuarta, actuando como un instrumento que permite explorar los límites de la representación de la memoria y de la identidad de esos grupos y acontecimientos que carecen de espacio de representación, generalmente relacionados con sucesos trágicos o traumas sociales.

Pero antes de pasar a describir esas cuatro modalidades ideales de acción, resultaría interesante realizar algunas consideraciones generales en torno al patrimonio como tecnología y que se sustentan en los dos ejes que definirían la sociedad del conocimiento: la cultura experta y la gubernamentalidad postmoderna.

Como afirmaba en la primera parte de este texto, de un tiempo a esta parte se ha configurado un espacio al que ha accedido, mediante la intermediación experta, la biopolítica: el del sentido de pertenencia, el de las identidades, el de lo cultural. Con el patrimonio, la gubernamentalidad alcanza su máximo grado de expresión: por un lado, pretende gobernar incluso los espacios del vacío, de la nada, de la ruptura; por otro lado, intenta buscar una solución técnica para aquello que nunca se había prestado al frío cálculo de lo científico-racional: las identidades, lo social, lo comunitario, en definitiva, los grandes referentes del sentido, convirtiéndolos en lugar de trabajo y problematización del experto.

El patrimonio viene a espolear al individuo a que sea sujeto activo de la representación patrimonial, a que participe del andamiaje tecnológico que lo sustenta; se le exhorta también a que se constituya como usufructuario o propietario del patrimonio; se le incita, y en ocasiones obliga, a experimentar, a ser un sujeto de la experiencia. La proliferación de ecomuseos, 
museos-territorio, itinerarios culturales, escuelas-taller, parques temáticos, ciudades-patrimonio, circuitos culturales o parques naturales, entre otros muchos, todos ellos empujan a la interacción, a la participación, a la vivencia. Se ha pasado del conservador "prohibido tocar" al "prohibido no tocar" (Prats 1997: 49, nota 13).

Según las racionalidades políticas contemporáneas, las del liberalismo avanzado, se pretende crear individuos-ciudadanos activos, que se autorregulen no ya desde la amenaza del panóptico que crea cuerpos dóciles a la disciplina, sino, como ya señalé más arriba, desde el ejercicio de su libertad individual. Como bien afirma Rose, la subjetividad, la agencia, la libertad, y el deseo [will], no se oponen al poder o a la tecnología, sino que son el resultado de unas configuraciones concretas de poder, de ciertas invenciones tecnológicas, o de ciertas técnicas más o menos racionalizadas de relacionarlos con nosotros mismos (Rose 1999b: 54-55). Precisamente, puesto que el poder no es ninguna sustancia, es un tipo específico de establecer relaciones entre individuos, requiere de la existencia de algún tipo de libertad, aunque fuera mínimo, ya que "no hay poder sin que haya rechazo o rebelión en potencia" (Foucault 1990: 139). Así, es posible entender el patrimonio como una tecnología que ayuda a construir un amplio sentido de la libertad individual, una agencia activa, el deseo de la experimentación, y la unión de individuos que se representan (individual o colectivamente) como sujetos adscritos a una comunidad de sentido.

Y en todo esto, juega un papel fundamental la teatralización y espectacularización del patrimonio, consecuencia de la forma en la que se materializa esta tecnología de gobierno, y que mostraré con mayor detalle más adelante. Es por esto que García Canclini (2001) considera que el patrimonio es fuerza política, es poder, en la medida en que se teatraliza, se escenifica, o que, siguiendo a Gatti (2002), se pueda considerar el patrimonio como el modo en el que la identidad se objetiva, se convierte en una entidad visible y autónoma, en definitiva, en cómo el patrimonio "constituye a la identidad en espectáculo" (Gatti 2002: 126).

\section{Reviviendo el pasado: espacio de excepción}

En mi opinión este es el uso tecnológico más común del patrimonio. El patrimonio cultural, en mayor o menor medida, siempre hace referencia a algo relacionado con el pasado. No existe el patrimonio de lo que será,

8 Cita extraída por Prats a su vez de Montaner, Josep María (1996). "Toque, por favor" en EL PAIS, edición Cataluña, 21-09-1996. 
siempre es acerca de lo que fue una vez y ya no es. Sabemos, por ejemplo, que hay nuevos tipos de patrimonios que emergen día a día, como el de la era digital, pero incluso en esos casos, debe existir un objeto obsoleto, siempre dentro de lo que puede ser considerado como tal en un universo dado (por ejemplo, diez ańos para un videojuego o un equipo informático puede ser considerado una eternidad).

Este carácter instrumental del patrimonio puede verse como el resultado de esa gubernamentalidad postmoderna de la que ya he escrito varias veces en el presente artículo. Como sabemos, el objetivo de la biopolítica es cuidar de la población que cae bajo su preocupación, manteniéndola viva, sana, segura, próspera. Como afirma Foucault (2003), el biopoder es cada vez menos el derecho sobre la muerte (el poder del soberano) y cada vez más el derecho sobre la vida (desde finales del siglo XVIII). En este caso el patrimonio parece ir más lejos: es capaz de revivir aquello que está muerto. Por supuesto, se trata de un modo figurativo de renacimiento ya que el patrimonio apunta a los dominios del sentido, siendo su preocupación por las poblaciones semántica, no biológica. En este caso, el patrimonio cultural funciona como una poderosa fórmula de semiopoder, que recrea extintos mundos sociales en unas circunstancias socio-materiales que le son hostiles. Podemos imaginar todo tipo de cosas que, literalmente, han pasado a mejor vida, se encuentran virtualmente o completamente en ruinas, o sus significados han sido vaciados, pero que ahora, gracias a las redes expertas que soportan el patrimonio, han sido revividas, reconstruidas, simuladas o resignificadas.

Estos enunciados dejan, al menos, dos interrogantes principales. El primero, ¿cuáles son las implicaciones de otorgarle al patrimonio semejante poder, el de revivir cosas? El patrimonio, como las novelas de ciencia ficción, es presentado en muchas ocasiones como una máquina del tiempo que puede satisfacer el irrevocable sentido del pasado, y "no solamente conocerlo, sino verlo y sentirlo" (Lowenthal 1985: 14). Y esta tendencia de hacer a la gente partícipe de esos pasados, intentando darles una experiencia completa de cómo ellos podrían haber sido, es una forma muy efectiva de reinventar (o en ocasiones condicionar) las identidades.

Entonces, revivir el pasado tiene su impacto en las identidades presentes, lo cual nos dirige a la otra gran cuestión que quedaba pendiente: ¿cómo es esto posible?, ¿cómo puede el patrimonio alcanzar el milagro de la resurrección? El patrimonio cultural aparece en estas ocasiones como un espacio de excepción que comprende la suspensión de algunas condiciones sociales 
y materiales de existencia que constituyen el orden social, cultural, político, legal, físico o natural contemporáneo. Funcionaría como un laboratorio cognitivo y material que permitiría controlar algunas variables del entorno para facilitar la entrada, teatralizada, recreada o interpretada, de esas cosas que ya no son. Pero como buena tecnología gubernamental postmoderna, el patrimonio cultural funciona desde una excepcionalidad institucionalizada, normalizada (Agamben 2004).

\section{Haciendo de la identidad una rutina: proceso de traducción}

Otra de las formas en las que el patrimonio ayuda a moldear las identidades, estriba en su capacidad de hacer de estas algo rutinario, un estándar, una fórmula. La intervención técnica y experta en el mundo sociocultural, tiene como consecuencia la traducción de las identidades en códigos científico-expertos, que permiten su rutinización, haciéndolas comparables, contrastables y, sobre todo, reproducibles.

De hecho, nos encontramos con que en muchas ocasiones, aquellos elementos tradicionales que no han pasado por el tamiz de la ciencia, por el rigor técnico y la profesionalización de los expertos, en definitiva, que no se han insertado adecuadamente en la red experta del patrimonio y han sido traducidas a sus códigos, malviven y están abocados al fracaso, como es el caso de multitud de museos comarcales que proliferaron en España durante los ańos de la transición, la mayoría hoy día extintos, o los que han sobrevivido "lo hacen en un estado de completa momificación" (Prats 1997: 84). La forma cuasi-amateur de llevar esos museos, contrasta con la profesionalización y tecnificación de ciertas actividades consideradas patrimonio folclórico o popular, como lo demuestran los casos de la representación por parte de profesionales de la sardanha catalana (Howard 2003: 91), el aurresku vasco (ver http://www.euskalnet.net/aurresku/), el senderismo y sus caminos homologados, o, cómo hoy día, pueden venderse productos típicos que lo son porque cumplen unos cuidados procedimientos certificados científicamente.

De alguna manera, la red experta que sostiene el patrimonio cultural habilita la posibilidad de recortar las identidades, aislarlas, y singularizarlas, dejándolas listas para su representación, su experimentación, y su comercialización. De esta manera las identidades pueden andarse (diseño y señalización de senderos homologados que atraviesan diversos patrimonios culturales y naturales), navegarse (el e-patrimonio, o la digitalización del patrimonio para que puede consultarse vía web, haciendo visitas virtua- 
les), comerse (productos típicos ahora certificados por las denominaciones de origen, una forma de hacer patrimonio a los alimentos tradicionales), representarse (interpretar, como si de un espectáculo se tratara, danzas populares, ritos tradicionales, formas de vida extintas, o procesos de producción antiguos).

En definitiva, el patrimonio cultural, mediante la traducción de las identidades a códigos estándar, hace accesibles, con las limitaciones que también impone su excesiva profesionalización y comercialización, recursos culturales y sociales para que los individuos puedan experimentar con sus identidades y gestionar sus propios significados. Evidentemente, el principal riesgo al que se enfrentan en este caso aquellos que consumen estos patrimonios y por lo tanto, unas determinadas identidades, es la homogeneización de las mismas. Cuestión, por ejemplo, que ocurre cuando se observa que en muchas poblaciones indígenas se producen objetos, su patrimonio, acomodándose a cierta imagen de autenticidad, primitivismo y originalidad que hacen de sus productos algo más vendible (Pazos 1998: 38), asemejándose más bien a una producción en cadena que puede eliminar los matices de cada identidad indígena.

No obstante, no hay que perder de vista a figuras como la del parásito, desarrollada por Gatti (2002) en relación con su noción de modalidad débil de la identidad, identificada como estrategia, táctica o astucia que permite pensar, antes que en la identidad, en las maneras de disponerse ante las identidades, como un movimiento de algo que se busca y se construye, y no como algo que se es y ya se tiene (un propio). La astucia consiste en apropiarse de esos propios de las representaciones institucionalizadas de la identidad (modalidades fuertes), poseyéndolas y parasitándolas. Así, estas modalidades fuertes de la identidad pueden considerarse representaciones habitables, utilizadas (astutamente) por identidades precarias para refugiarse en ellas. También podría ocurrir esto con esas representaciones estandarizadas de la identidad que el patrimonio cultural puede llevar a cabo, pudiendo ser explotadas por formas creativas de consumo, habitándolas parasitariamente, estirándolas, pervirtiéndolas, dando lugar a nuevas configuraciones de identidad.

\section{Canalizando disputas: escenario técnico-experto}

Como ya se mencionó cuando realicé una pequeña genealogía del concepto de patrimonio y cómo éste se transforma, fruto de una serie de transiciones, en el patrimonio cultural que conocemos actualmente, podían 
identificarse dos significados dentro de dicho sintagma: uno activo y otro pasivo. El sentido activo del patrimonio cultural, lo estamos analizando en este apartado, trabaja como una tecnología que actúa sobre las identidades. Sin embargo, la acepción pasiva del mismo, tiende a definir el patrimonio cultural como un producto acabado, un listado de cosas, símbolos, costumbres y tradiciones que merecen ser conservados y que forman el acervo de un pueblo, grupo o comunidad.

Sin embargo, rara vez se puede considerar un patrimonio totalmente cerrado, acabado, incluso en los más consolidados. Siempre existe la posibilidad, otra cosa es que el patrimonio como ingenio tecnológico logre ahormar completamente las identidades y los significados-otros que pudiera contener, de contestación respecto a su propia naturaleza y sobre aquello que supuestamente se representa.

Es entonces cuando el patrimonio se convierte en un escenario experto dispuesto para canalizar diversas disputas en torno a la identidad y las cuestiones de sentido. Esto ocurre especialmente en los patrimonios más sensibles, más sujetos a la confrontación social por la disputa de su interpretación hegemónica.

Así, resulta preferible entender el patrimonio, antes que como un producto acabado que puede utilizarse como arma arrojadiza en diversas disputas, como un "campo de confrontación" en sí mismo, en el que conflictos, en apariencia, de carácter únicamente simbólico (sobre todo relacionados con identidades), se hacen espectacularmente visibles gracias a la materialidad que el patrimonio le dota a la disputa, lo que incluye todo tipo de acciones muy perceptibles, tales como "la destrucción del patrimonio o su apropiación y recalificación, o su sustitución” (Prats 1997:38).

El patrimonio, de esta manera, permite darle una materialidad y fisicidad a las disputas simbólicas sin parangón, lo que habilita todo tipo de soluciones técnicas a los procesos de negociación. No sin motivo, todo lo relacionado con el patrimonio, del mismo modo que todo lo que sucede en la llamada sociedad del conocimiento, está revestido de una reflexividad extrema: la identidad, la comunidad, la sociedad, la cultura, el nosotros mismos, son convertidos en objetos reflexivos por los propios integrantes de esas conjugaciones del sentido social:

En este sentido, el patrimonio no es más que la forma extrema y racionalizada de esa reflexividad consustancial a la vida social. El patrimonio sistematiza, objetiviza, legaliza y racionaliza una 
autoimagen preexistente en la sociedad de múltiples formas (Cruces 1998: 83).

Esa es la labor del patrimonio como tecnología: sistematizar, legalizar, y objetivar determinadas construcciones de sentido; sin embargo, no comparto en este caso la asunción que Cruces hace sobre la sistematización de una serie de autoimágenes preexistentes. Precisamente, la potencialidad del patrimonio estriba en dotar de un sustrato material, físico, objetivo, técnico, a aquello que tradicionalmente carecía de ello (o aunque lo tuviera, no estaba sujeto a acciones de gobierno y experticia), y permitir, en ese proceso, la emergencia de múltiples imágenes sobre lo propio, lo nuestro, que son contestadas, negociadas, luchadas, en definitiva, co-construidas. En ningún caso estaríamos ante corroboraciones objetivas de lo ya existente.

Aunque existe cierta tendencia a describir el patrimonio como instrumento para la unión de sentido (no es de extrañar, en su origen, explícitamente, y, actualmente, de forma más subyacente, está su labor clínica de suturar las fallas de sentido abiertas), es también un buen detector de las desigualdades sociales y culturales existentes dentro de una sociedad concreta según se convierte en "espacio de lucha material y simbólica entre las clases, las etnias y los grupos” (García Canclini 2001: 187).

\section{Transformando en patrimonio lo que no puede ser patrimonio: los limites de la representación}

Este sería el modelo de acción sobre las identidades más problemático del patrimonio. De hecho, se encontraría en la frontera entre lo que puede considerarse patrimonio y lo que no. Cuando se produce un acontecimiento traumático a nivel social, generalmente producido por hechos extremadamente violentos y con efectos devastadores, como pueden ser guerras, regímenes dictatoriales, catástrofes naturales, o situaciones muy graves de crisis económica, le suele suceder un vacío de sentido, es decir, se torna imposible, al menos directamente, intentar representar esos acontecimientos o épocas. Ahí es donde se "ubica[n] la imposibilidad de narrar y los huecos simbólicos de lo traumático" (Jelin 2002: 80), o lo que en su esfuerzo por hacer operativa una sociología del vacío social, Gatti (2005) plantea como su principal problema metodológico, la irrepresentabilidad del mismo.

El patrimonio cultural, como buen instrumento que intenta dotar de sentido lo presente a través de las representaciones que hace del pasado, aparece entonces como un intento de explorar los límites de esa imposibilidad. 
Sin embargo, la paradoja es doble: en primer lugar, pretende hacer coherente aquello que, por naturaleza, es inconexo, quebradizo, indecible; en segundo lugar, el patrimonio cultural está relacionado con aquello que deseamos conservar, ese bien común que nos enriquece; en definitiva, el patrimonio busca preservar aquello que merece ser conservado, sin embargo, en esta ocasión sirve para retener aquello que quisiéramos que nunca hubiese ocurrido, algo que no es motivo de orgullo, riqueza o valor.

Y en esa tensión paradójica en la que se mueve el patrimonio cultural cuando aborda la catástrofe social es donde puede ayudar a vislumbrar, más bien lateralmente, las (no-)identidades precarias, liminares, escurridizas. De cualquier forma, es un debate que en lugar de insertarse directamente en la problemática del patrimonio cultural se suele situar en el de la memoria, que en ocasiones busca una uniformidad incompatible con la naturaleza de $l o$ memorado, remitiéndonos de nuevo a un espacio de lucha y confrontación, donde aflorarán identidades negadas en otro tiempo o nuevas formulaciones de viejas identidades sustentadas durante muchos años.

Me gustaría mencionar de nuevo que el esquema presentado solamente puede ser considerado desde un punto de vista estrictamente analítico. No son, en ningún caso, acciones excluyentes, ya que en muchas ocasiones se apoyan unas sobre otras y resulta muy complicado encontrar un patrimonio que funcione exclusivamente según uno de los modelos de acción descrito más arriba. En todos los casos, la labor experta, técnica y profesional, siempre resulta indispensable.

De cualquier manera, quizás también fuera prudente incluir una modalidad especial de acción sobre la identidad que esté basada, no en una forma directa de intervención por parte del entramado experto, sino más bien en depositar en los propios ciudadanos o usufructuarios de un patrimonio las herramientas necesarias para gestionar su propio espacio social, tal y como es señalado por Newman et al. (2005) en su investigación sobre proyectos museísticos en zonas deprimidas de Newcastle upon Tyne y Glasgow (Reino Unido) en el que "se utiliza la cultura como una manera de ayudar a resolver problemas de exclusión social” (Newman et al. 2005: 54). De nuevo, el patrimonio como ese artefacto que permite remendar determinados desajustes de origen social. 


\section{Conclusión}

A modo de breve conclusión se puede decir que la sociedad del conocimiento es el espacio-tiempo sociohistórico en el cual la institucionalización de la biopolítica y la creación de una cultura experta alcanzan su apoteosis, momento en el que apenas existe superficie alguna que no haya sido colonizada por la labor experta y las técnicas de gobierno, y donde únicamente somos capaces de volver, una y otra vez, sobre los artefactos que hemos ido depositando sobre la realidad. En este contexto el patrimonio aparece como una tecnología, una maquinaria, o un dispositivo para moldear identidades, troquelar sentimientos de pertenencia y diferencia, y administrar lo pasado, la memoria. Así es como queda patente en el siguiente extracto de un plan de ordenación patrimonial en Lleida (España), en el que se incluía la construcción de un ecomuseo:

Pero es que, además, a partir de estos equipamientos, la población de la comarca, con el auxilio de los técnicos, dispone de un instrumento permanente de investigación, de reflexión sobre su pasado, su presente y su futuro, $y$, por tanto, para la construcción de su identidad (Prats 1997: 144).

El patrimonio sirve pues -a través de la reflexividad, la total visibilidad, y la mano del experto-, para construir identidades allí donde no las hay o donde las hubo y se quieren modificar las que existen.

\section{BibliografíA}

Agamben, G. 2004. Estado de excepción. Homo sacer II, 1. Pre-textos, Valencia.

Arińo, A. 2002. "La patrimonialización de la cultura y sus paradojas en la sociedad del riesgo". En ¿Más allá de la modernidad? Las dimensiones de la información, la comunicación y sus nuevas tecnologías, editado por J. M. García Blanco, y P. Navarro Sustaeta, pp: 329-352. CIS, Madrid.

Ballart, J. y J. J. Tresserras. 2005. Gestión del patrimonio cultural. Ariel, Barcelona.

Baudrillard, J. 1984. Cultura y simulacro. Kairós, Barcelona.

Beck, U. 1998. La sociedad del riesgo. Hacia una nueva modernidad. Paidós, Barcelona.

Bell, D. 1994. El advenimiento de la sociedad post-industrial. Un intento de prognosis social. Alianza, Madrid. 
Bermejo, J. C. 2005. "La ideología del patrimonio y el nacimiento de la historia basura. Xornal da USC, Jueves 18-05-2005. http:// www.usc.es/gl/xornal/ opinions.action?id=14290.

Castells, M. 2000. La era de la información. Economía, sociedad y cultura. Vol. 1. La sociedad red. Alianza, Madrid.

Castells, M. 2001a. La era de de la Información. Economía, sociedad y cultura. Vol. 2. El poder de la identidad. Alianza, Madrid.

Castells, M. 2001b. La era de la información. Economia, sociedad y cultura. Vol. 3. Fin de milenio. Alianza, Madrid.

Cruces, F. 1998. "Problemas en torno a la restitución del patrimonio. Una visión desde la antropología”. Politica y Sociedad 27: 77-87

Dean, M. 1999. Governmentality. Power and Rule in Modern Society. Sage, Londres.

Drucker, P. F. 1998. La sociedad postcapitalista. Apóstrofe, Barcelona.

Foucault, M. 1990. Tecnologías del yo. Y otros textos afines. Paidós, Barcelona.

Foucault, M. 2003. Hay que defender la sociedad. Akal, Madrid.

García Canclini, N. 2001. Culturas hibridas. Estrategias para entrar y salir de la modernidad. Paidós, Barcelona.

Gatti, G. 2002. Las modalidades débiles de la identidad. Servicio Editorial UPV, Bilbao.

Gatti, G. 2005. "La teoría sociológica visita el vacío social (o de las tensas relaciones entre la sociología y un objeto que le rehúye)". En Las encrucijadas de la diversidad cultural, editado por A. Ariño. pp: 177-200. CIS, Madrid.

Gatti, G. y D. Muriel 2006. "El patrimonio, en el quicio de lo viejo y lo nuevo". En La producción de la identidad en la sociedad del conocimiento. Cultura experta e identidad en el País Vasco, editado por G. Gatti e I. Martínez de Albeniz, pp: 25-67. Cuadernos Azkoaga. Eusko Ikaskuntza, Donostia.

Howard, P. 2003. Heritage: Management, Interpretation, Identity. Continuum, Londres.

Jelin, E. 2002. Los trabajos de la memoria. Siglo XXI, Buenos Aires.

Lamo de Espinosa, E. 1996. Sociedades de cultura, sociedades de ciencia. Ensayos sobre la condición moderna. Nobel, Oviedo.

Latour, B. 2001. La esperanza de Pandora. Ensayos sobre la realidad de los estudios de la ciencia. Gedisa, Barcelona. 
Latour, B. y S. Woolgar. 1995. La vida en el laboratorio. La construcción de los hechos cientificos. Alianza, Madrid.

Lowenthal, D. 1985. The past is a foreign country. Cambridge University Press, Cambridge.

Miller, P. y N. Rose. 1992. "Political power beyond the State: problematics of government”. British Journal of Sociology 43 (2): 173-205.

Muriel, D. 2005. “(In)transitabilidades hacia la sociedad del conocimiento: una lectura crítica de la producción sociológica moderna”. Confines de relaciones internacionales y ciencia politica 2: 19-34.

Newman, A., F. McLean y G. Urquhart. 2005. "Museums and the Active Citizen: Tackling the Problems of Social Exclusion". Citizenship Studies 9(1): $41-57$.

Pazos, A. 1998. "La re-presentación de la cultura. Museos etnográficos y antropología”. Politica y Sociedad 27: 33-45.

Prats, Ll. 1997. Antropología y patrimonio. Ariel, Barcelona.

Rose, N. 1999a. Powers of freedom. Reframing political thought. Cambridge University Press, Cambridge.

Rose, N. 1999b. Governing the soul. The shaping of the private self. Free Association Books, Londres.

Rose, N. 2007. The politics of Life Itself. Biomedicine, Power, and Subjectivity in the Twenty-First Century. Princeton University Press, New Jersey.

Santamarina, B. 2005. "Una aproximación al patrimonio cultural". En La memoria construida. Patrimonio cultural y modernidad, editado por G. Hernández, B. Santamarina, A. Moncusi y M. Rodrigo, pp: 21-51. Tirant Lo Blanch, Valencia.

Seguel, A.G. 2005. "De símbolos y hackers: guías en la sociedad del conocimiento". Liminar, Estudios sociales y humanísticos III (1): 108-119.

Stehr, N. 1994. Knowledge Societies. Sage, Londres.

Tirado, F. J. y A. M. Gálvez. 2004. "El poder como prehensión. Superficies de ensamblaje y producción de dividuos". II Congreso on-line del Observatorio para la CiberSociedad http://www.cibersociedad.net/congres2004/grups/fitxacom_ publica2.php?grup=14\&id=624\&idioma=es . 